\title{
HALLAZGO DE UNA NUEVA ESPECIE DE AGARISTA (ERICACEAE) EN JALISCO, MEXICO
}

\author{
Luz Maria Gonzalez V. \\ Instituto de Botánica \\ Universidad de Guadalajara \\ Apartado postal 139 \\ Zapopan, Jalisco 45110
}

\section{RESUMEN}

Se describe Agarista villarrealana, sp. n., proveniente de la Sierra Madre del Sur, Jalisco, México. Pertenece a la sección Agaristay se distingue facilmente de las especies conocidas para México, por ser un arbustito rizomatoso de menos de $1 \mathrm{~m}$ de alto, con hojas coriáceas y flores rojas. La especie con la que más se podría relacionar es $A$. pulchella Cham. ex G. Don var. pulchella del sureste de Brasil.

\section{ABSTRACT}

Agarista villarrealana sp. $\mathrm{n}$., from the Sierra Madre del Sur, Jalisco, México, is described. The species is a member of section Agarista and is easily distinguished from the other species of Agarista known from Mexico because it is a rhizomatous shrub less than $1 \mathrm{~m}$ tall with coriaceous leaves and red flowers. It is probably related to Agarista pulchella Cham. ex G. Don var. pulchella from southeastern Brazil.

Durante la preparación de la familia Ericaceae para la flora de Jalisco, en el mes de abril de 1987 se colectó en los alrededores de la mina Zimapán, municipio de Talpa de Allende, una pequeña planta previa a la antesis, que por su tamaño, follaje y forma de desarrollo parecía representar una especie de Gaultheria. Un mes después regresamos al área y nos encontramos la población en floración. Al estudiarla con detalle se determinó que corresponde al género Agarista, pero al no coincidir sus características con ninguno de los miembros citados en el trabajo de Judd (1984) se concluyó que se trata de una novedad.

Esta planta se conoce hasta el momento, de una sola localidad, lo que explicaría que no haya sido colectada con anterioridad y se propone como nueva especie bajo el siguiente nombre:

Agarista villarrealana González V., sp. n., (Fig. 1)

Frutex pusillus $10-50 \mathrm{~cm}$ altus. Ramuli leviter vel dense pubescentes, medulla regulariter septata. Folia ovata vel lanceolata, (1.5-)3-3.5(-4.3) cm longa, (0.6-)1.5(-2.7) cm lata, coriacea, leviter conduplicata, ascendentia, apice late acuta usque ad acuminata, ad basim rotundata vel cordata, margine integra leviter revoluta, utrinque pilis simplicibus sparsis praecipue ad costam limitatis munita; petioli (2-)5(-8) $\mathrm{mm}$ longi. Inflorescentiae racemosae, axillares, (1.3-)2-2.5(-4) cm longae, rhachide dense pubescenti. Pedicelli (4-)6-7(-8) mm longi. Calyx lobis (1.7-)2-2.5 mm longis, (1.5-)1.8-2(-2.5) mm latis, dense pubescentibus. Corolla 
cylindrica 7-10 mm longa, (2-)3-4(-4.5) mm lata, rubra, leviter pilosa. Filamenta (4.5-)5.7-6.5 $(-7) \mathrm{mm}$ longa, pilosa; antherae 1.5-2 $\mathrm{mm}$ longae. Ovarium pubescens. Capsula brevissime ovoidea vel subglobosa, (4-)5-6(-6.5) mm longa, (3-)4(-5) $\mathrm{mm}$ lata, placentis subapicalibus. Semina(1.5-)1.7-2.3 mm longa.

Arbustito rizomatoso, erecto, poco o no ramificado, de $10-50 \mathrm{~cm}$ de alto, corteza delgada, tallos rojizos, médula regularmenre septada; ramillas rígidas, ascendentes, moderada a densamente pubescentes con los pelos simples, café a café-rojizas; yemas de (1-)1.5-2 mm de largo; peciolos de (2-)5(-8) mm de largo; hojas ovadas a lanceoladas, alternas a subopuestas o casi en verticilos de 3, de (1.5-)3-3.5(-4.3) cm de largo, de(0.6-)1.5(-2.7) cm de ancho, coriáceas, levemente conduplicadas, ascendentes, ápice ampliamente agudo a acuminado, margen entero ligeramente revoluto, base redondeada, a veces subcordada, haz y envés con pelos simples esparcidos principalmente confinados a la nervadura central, envés a veces totalmente glabro, con pocas e inconspicuas manchas glandulares a lo largo de la nervadura principal; inflorescencias racimosas, axilares, rara vez terminales, de (1.3-)2-2.5(-4) cm de largo, de 8-12 flores por racimo, raquis con una diminuta y densa pubescencia blanquecina; pedicelos densamente pubescentes, de (4-)6-7(-8) $\mathrm{mm}$ de largo, con una articulación de posición variable de 0.25-1 mm abajo de la inserción del cáliz; brácteas de (1.3-)2(-2.7) mm de largo; bracteolas 2, basales, alternas a opuestas, lineares, de (1.2-)1.5-2.5(-4.5) mm de largo; lóbulos del cáliz triangulares con ápices acuminados, de (1.7-)2-2.5 mm de largo, de (1.5-)1.8$2(-2.5) \mathrm{mm}$ de ancho, densamente pubescentes; corola cilíndrica de 7-10 mm de largo, de (2-)3-4(-4.5) $\mathrm{mm}$ de ancho, roja, escasamente pilosa; filamentos vilosos, de (4.5-)5.7-6.5 (-7) $\mathrm{mm}$ de largo, anteras glabras de 1.5-2 $\mathrm{mm}$ de largo; ovario pubescente; cápsulas cortamente ovoides a subglobosas, de (4-)5-6(-6.5) $\mathrm{mm}$ de alto, de (3-)4(-5) $\mathrm{mm}$ de diámetro, pilosas, placenta subapical; semillas de (1.5-)1.7-2.3 mm de largo. Florece de mayo a junio (-julio) y fructifica de julio a agosto.

TIPO: México, Jalisco. Municipio de Talpa de Allende, El Caracol, al W de la mina Zimapán, alt. $2200 \mathrm{~m}$, arbustito rizomatoso de $15-20 \mathrm{~cm}$ de alto de flores rojas, localmente abundante sobre suelos rocosos, en pendientes de $15-20^{\circ}$, en bosque de pino y encino con asociación de Pinus oocarpa, $P$. douglasiana, P. herrerae, P. ayacahuite, Quercus ssp., Clethrasp., Vaccinium confertum, Befaria mexicana, Comarostaphylis spp., 24.V. 1987, González V. 3092 (holotipo: IBUG; isotipos: ENCB, FLAS, IEB, MEXU, NY, US,WIS).

Material adicional examinado: Jalisco, municipio de Talpa, El Caracol, al W de la mina Zimapán, Sierra de Cuale, alt. $2150 \mathrm{~m}$, en bosque de Pinus oocarpa, $P$. douglasiana, $P$. herrerae, $P$. ayacahuite, Quercus scytophylla, Q. laeta, Q. coccolobifolia, 22.IV.1987, Pérez de la Rosa 1362 (IBUG); Ibid., 12.VII.1987, González V. 3107 (IBUG), ejemplares con frutos.

Fig. 1. Agarista villarrealana. A. Rama con inflorescencias, $x 0.6$; B. Rama con infrutescencias, $x 0.6 ; C$. Flor, x10; D. Estambre, xll; E. Antera,X22; F. Cápsula, x5; G. Columela con placenta, x9; H. Semilla con células de la testa alargadas, $\times 10$; I. Sección transversal del tallo mostrando la porción central, $\times 8$; J. Detalle de la hoja con manchas glandulares $\times 7 ; \mathrm{K}$. Pelo unicelular del pedicelo, $\times 46$. 
González: Una Nueva Especie de Agarista

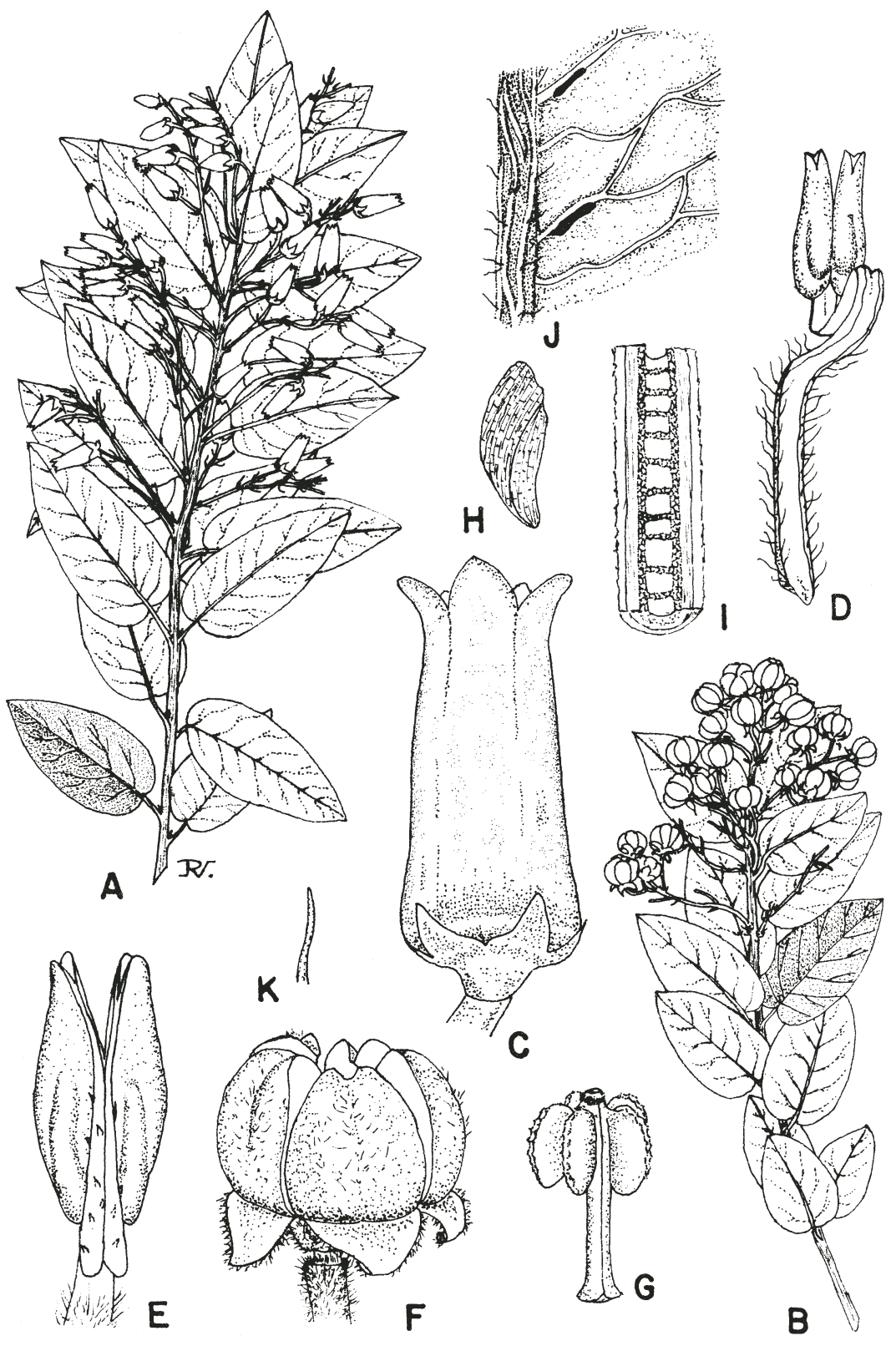


El área de distribución de esta especie denota al parecer un endemismo muy marcado, pues sólo se ha visto en un área de menos de un kilómetro cuadrado en la cima de una montaña rica en minerales. Además, se pudo observar que dicha área se encuentra sometida a la acción periódica del fuego. Sin embargo, no se descarta la posibilidad de su presencia en otras partes similares de la Sierra de Cuale.

Al comparar Agarista villarrealana con las especies reconocidas por Judd (1984), la relacionamos con $A$. pulchella Cham. ex G. Don var. pulchella, pues ambas son arbustos de hojas coriáceas más o menos similares en tamaño y disposición. Sin embargo, la distinción está en que $A$. pulchella var. pulchella presenta ramillas con o sin pelos glandulares capitados, médula aseptada a irregularmente septada, hojas más o menos ovadas con el ápice redondeado o agudo-mucronado, inflorescencias hasta de $12 \mathrm{~cm}$ de largo, cápsulas con placenta más o menos central (rara vez subapical) y semillas considerablemente más pequeñas en comparación con $A$. villarrealana. $A$. villarrealana se diferencia porque sus ramillas carecen completamente de pelos glandulares capitados, médula regularmente septada, hojas ovadas a lanceoladas con el ápice ampliamente agudo a acuminado, inflorescencias hasta de $4 \mathrm{~cm}$ de largo y cápsulas con placenta subapical. Las dos especies están geograficamente separadas, A. pulchella var. pulchella está restringida al sureste de Brasil (Cuadro 1).

Sin embargo, una posible relación con $A$. mexicana puede estar indicada por la presencia en $A$. villarrealana de una médula regularmente septada, hojas ovadas a lanceola-

Cuadro 1. Comparación de algunos caracteres de Agarista villarrealana, A. pullchella var. pulchella y A. mexicana.

\begin{tabular}{|c|c|c|c|}
\hline Carácter & A. villarrealana & A. pulchella var. pulchella & A. mexicana \\
\hline Hábito & $\begin{array}{c}\text { arbusto de } 10-50 \mathrm{~cm} \\
\text { de alto }\end{array}$ & arbusto de $2(-3) \mathrm{m}$ de alto & $\begin{array}{c}\text { arbusto o árbol hasta de } \\
8(-11) \mathrm{m} \text { de alto }\end{array}$ \\
\hline Ramillas & $\begin{array}{l}\text { carentes de pelos } \\
\text { glandulares capitados }\end{array}$ & $\begin{array}{c}\text { con o sin pelos } \\
\text { glandulares capitados }\end{array}$ & $\begin{array}{l}\text { carentes de pelos } \\
\text { glandulares capitados }\end{array}$ \\
\hline Médula & regularmente septada & $\begin{array}{c}\text { aseptada a irregularmente } \\
\text { septada }\end{array}$ & $\begin{array}{c}\text { regularmente septada a } \\
\text { aseptada }\end{array}$ \\
\hline Yemas (largo) & $(1-) 1.5-2 \mathrm{~mm}$ & aprox. $1 \mathrm{~mm}$ & aprox. $1.5 \mathrm{~mm}$ \\
\hline Hojas (largo) & $\begin{array}{c}\text { ovadas a lanceoladas } \\
(1.5-) 3-3.5(-4.3) \mathrm{cm}\end{array}$ & $\begin{array}{c}\text { más o menos ovadas } \\
1.2-4(-5) \mathrm{cm}\end{array}$ & $\begin{array}{c}\text { ovadas a lanceoladas } \\
2-7.5(-9) \mathrm{cm}\end{array}$ \\
\hline Apice de hojas & $\begin{array}{c}\text { ampliamente agudo a } \\
\text { acuminado }\end{array}$ & $\begin{array}{l}\text { redondeado a agudo, } \\
\text { mucronado }\end{array}$ & acuminado \\
\hline Base de hojas & $\begin{array}{c}\text { redondeada a veces } \\
\text { subcordada }\end{array}$ & claramente cordada & cuneada a redondeada \\
\hline Peciolos (largo) & $(2-) 5(-8) \mathrm{mm}$ & $1.5-5 \mathrm{~mm}$ & $2-12.5 \mathrm{~mm}$ \\
\hline $\begin{array}{c}\text { Inflorescencias } \\
\text { (largo) }\end{array}$ & $(1.3-) 2-2.5(-4) \mathrm{cm}$ & $2-7(-12) \mathrm{cm}$ & $0.5-2.5(-4) \mathrm{cm}$ \\
\hline Lóbulos del cáliz & $\begin{array}{c}(1.7-) 2-2.5 \text { por }(1.5-) 1.8-2 \\
(-2.5) \mathrm{mm}\end{array}$ & 1.4-2.6 por $0.8-1.5 \mathrm{~mm}$ & $0.9-1.8$ por $0.5-2 \mathrm{~mm}$ \\
\hline Corola & roja & blanca a roja & blanca \\
\hline Placenta & subapical & más o menos central & subapical \\
\hline Semilla (largo) & $(1.5-) 1.7-2.3 \mathrm{~mm}$ & $0.8-1.3 \mathrm{~mm}$ & $1.5-2.7 \mathrm{~mm}$ \\
\hline
\end{tabular}


das, inflorescencias claramente pequeñas, cápsulas con placenta subapical y semillas de 1.7$2.3 \mathrm{~mm}$ de largo (véase Cuadro 1).

La nueva especie también se encuentra aislada de $A$. mexicana; la población más cercana conocida está aproximadamente a $10 \mathrm{~km}$ de distancia, a $2020 \mathrm{~m} \mathrm{s.n.m.}$

El nombre del taxon nuevo se dedica a la profesora Luz María Villarreal de Puga, por su destacada labor en la enseñanza de la botánica, no menos reconocida por su contribución con numerosas colectas para la flora de Jalisco y quién además orgullosamente es mi madre.

\section{AGRADECIMIENTOS}

Agradezco a la Universidad de Guadalajara su apoyo económico otorgado mediante acuerdos 85-01/263 y 86/MB/0331/01/0260 para el proyecto "Contribución al conocimiento de la familia Ericaceae en el Estado de Jalisco", a través del Departamento de Investigación Científica y Superación Académica, con lo que se logró el hallazgo de la especie que ahora se publica. En forma muy especial al Dr. Jerzy Rzedowski por la revisión y valiosas observaciones al manuscrito. A Roberto González Tamayo por la diagnosis en latín y sugestiones durante la preparación del manuscrito, a Ma. del Refugio Vázquez Velasco por su eficiencia en la ilustración, a Raymundo Ramírez Delgadillo, inestimable auxiliar del proyecto, y a Jorge Alberto Pérez de la Rosa por su apoyo moral y compañía en los trabajos de campo.

\section{LITERATURA CITADA}

Judd, W. S. 1984. A taxonomic revision of the American species of Agarista (Ericaceae). J. Arnold Arb. 65: 255-342. 